\title{
Anti-Corrosive Behavior of the Seed Extract of Amomum sabulatum
}

\author{
Neha Daksh ${ }^{\mathrm{a}}$, Akhil Saxena*, Jayahari Lade ${ }^{\mathrm{b}}$, Nakul Gupta ${ }^{\mathrm{c}}$

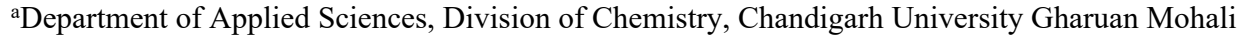 \\ ${ }^{b}$ KG Reddy College of Engineering and Technology \\ 'Department of Civil Engineering Mathura
}

\begin{abstract}
An aqueous extract of Amomum sabulatum seeds was evaluated for anticorrosive effects on mild steel in the presence of $\mathrm{HCl}$. Weight loss measurements were taken to determine the corrosion rate and inhibition efficiency at various concentrations. With the increasing concentrations of plant extract, the results showed an improvement in inhibition efficiency and a decrease in corrosion rate. In the presence of $1500 \mathrm{ppm}$ concentration of plant extract, it has an inhibition efficiency of $82.08 \%$ at $303 \mathrm{~K}$. The scanning electron microscope was used to examine the surface, which proves that while the extract was there, a protective layer formed on the metal surface.
\end{abstract}

Keywords- Inhibition efficiency, Amomum sabulatum seeds, SEM, weight loss measurements, adsorption isotherm, corrosion.

\section{Introduction}

Corrosion is the degradation of physical, metallurgical, and mechanical qualities of materials caused by a chemical or electrochemical attack. It is one of the confined or uniform 'genetic infections' of metals and their compounds. Nowadays acidic corrosion is very common as acid solutions are widely utilised in a variety of industrial procedures, including acid pickling, commercial acid cleaning, acid ultrasonic cleaning, and acidizing oil wells.. The life of metallic components is then jeopardised, and their service life may be drastically decreased. As a result, scientists are constantly seeking for new techniques to reduce the rate of corrosion of metallic components, particularly mild steel, in acidic environments. Because of their extensive range of industrial applications, particularly in the petroleum industry and power plants, mild steel and especially its alloys have been the focus of countless studies. Several methods have been utilised to overcome the corrosion process of mild steel, and the effective methods applied are the use of corrosion inhibitors. Organic chemicals have been employed as corrosion inhibitors in several earlier investigations. These compounds frequently contain nitrogen and oxygen atoms, as well as some effective groups, which aid in their adsorption on the surface of steel, reducing corrosion rates and improving inhibition efficiency.

Many scientists have recently become interested in the use of natural, organic plant extracts as green corrosion inhibitors. Green corrosion inhibitors provide a number of advantages over chemical corrosion inhibitors, including the fact that they are disposable, harmless, ecologically friendly, and ecologically tolerable, in addition to being costeffective, readily available, renewable, and safe to use. Natural chemicals present in herb plants, for example, have lately been employed as inhibitors in the development of new green cleaning solutions. Several research on the use of natural compounds as corrosion inhibitors in various media have been published. The majority of natural goods are harmless, biodegradable, and widely available. Plant parts such as seeds, fruits, flowers, and leaves, were isolated and employed as corrosion inhibitors.

\section{Weight loss measurements}

One of the simplest approaches for determining corrosion inhibition efficiency is to evaluate weight 
loss. For this measurement mild steel plate was cut with the dimensions of $1 \mathrm{x} 1 \mathrm{~cm}^{2}$. All the mild steel plate specimens were mirror finished by abrading with 100-1200 grades of emery paper.

Before starting the experimental process, all the dried MS specimens were carefully weighed on the analytical balance and reported as the initial weight of the mild steel plate. These specimens were subsequently dipped into a beaker containing $100 \mathrm{~mL}$ of test solution (prepared by using different concentrations of stock solution diluted with $1 \mathrm{M}$ $\mathrm{HCl})$ via the hole, thread, and capillary. Test specimens were taken out after 24 hours of exposure to an acidic solution and rinsed with acetone and dried. The dried specimens were correctly reweighted after immersion. In the absence, presence and increasing concentrations of the inhibitor extract, the weight loss was measured by subtracting the weights of the samples before and after hanging them in the corrosive solution.

The percentage inhibition efficiency $(\eta \%)$ and surface coverage $(\theta)$ is being calculated by the use of formulas shown below and shown in Fig.1.

$$
\begin{gathered}
\eta \%=\frac{w 0-w i}{w 0} \times 100 \\
\theta=\frac{w 0-w i}{w 0}
\end{gathered}
$$

\begin{tabular}{|c|c|c|c|c|c|c|}
\hline N & $\begin{array}{l}\text { Concentra } \\
\text { tion of } \\
\text { solution }\end{array}$ & $\begin{array}{l}\text { Initi } \\
\text { al } \\
\text { weig } \\
\text { ht of } \\
\text { mild } \\
\text { steel } \\
\text { plate } \\
{\left[\mathrm{w}_{0}\right]} \\
\text { (in } \\
\text { g) }\end{array}$ & $\begin{array}{l}\text { Fina } \\
1 \\
\text { weig } \\
\text { ht of } \\
\text { mild } \\
\text { steel } \\
\text { plate } \\
{\left[\mathrm{w}_{\mathrm{i}}\right]} \\
\text { (in } \\
\mathrm{g})\end{array}$ & $\begin{array}{l}\text { Wei } \\
\text { ght } \\
\text { loss } \\
{\left[\mathrm{w}_{0}-\right.} \\
\left.\mathrm{w}_{\mathrm{i}}\right]\end{array}$ & $\begin{array}{l}\text { Inhibit } \\
\text { ion } \\
\text { efficie } \\
\text { ncy } \\
\text { (in \%) }\end{array}$ & $\begin{array}{l}\text { Surfac } \\
\text { e } \\
\text { cover } \\
\text { age } \\
(\theta)\end{array}$ \\
\hline 1. & 0 & $\begin{array}{l}6.91 \\
8\end{array}$ & $\begin{array}{l}5.20 \\
3\end{array}$ & $\begin{array}{l}1.71 \\
5\end{array}$ & - & - \\
\hline 2. & 100 & $\begin{array}{l}6.82 \\
8\end{array}$ & $\begin{array}{l}5.60 \\
0\end{array}$ & $\begin{array}{l}1.22 \\
8\end{array}$ & 28.39 & 0.28 \\
\hline 3. & 200 & $\begin{array}{l}6.50 \\
6\end{array}$ & $\begin{array}{l}5.56 \\
5\end{array}$ & $\begin{array}{l}0.94 \\
1\end{array}$ & 45.13 & 0.45 \\
\hline 4. & 300 & $\begin{array}{l}7.01 \\
3\end{array}$ & $\begin{array}{l}6.09 \\
0\end{array}$ & $\begin{array}{l}0.92 \\
3\end{array}$ & 46.18 & 0.46 \\
\hline
\end{tabular}

\begin{tabular}{|l|l|l|l|l|l|l|}
\hline 5. & 400 & 6.99 & 6.19 & 0.79 & 53.64 & 0.53 \\
3 & 8 & 5 & & \\
\hline 6. & 500 & 7.06 & 6.33 & 0.73 & 57.20 & 0.57 \\
& & 8 & 4 & 4 & & \\
\hline 7. & 600 & 6.25 & 5.82 & 0.43 & 74.51 & 0.74 \\
& & 8 & 1 & 7 & & \\
\hline 8. & 700 & 5.94 & 5.28 & 0.66 & 61.22 & 0.61 \\
& & 9 & 4 & 5 & & \\
\hline 9. & 800 & 5.68 & 5.13 & 0.55 & 67.69 & 0.67 \\
& & 7 & 3 & 4 & & \\
\hline 10 & 900 & 5.49 & 5.08 & 0.40 & 76.20 & 0.76 \\
. & & 3 & 5 & 8 & & \\
\hline 11 & 1000 & 6.11 & 5.75 & 0.36 & 78.71 & 0.78 \\
. & & 9 & 4 & 5 & & \\
\hline 12 & 1500 & 6.19 & 5.88 & 0.30 & 82.09 & 0.82 \\
. & & 4 & 7 & 7 & & \\
\hline
\end{tabular}

Inhibition efficiency- The efficiency of inhibition increases as the concentration of plant extract increases as shown in the graph given below-

\begin{tabular}{|l|l|l|}
\hline Sr.no. & $\begin{array}{l}\text { Concentration of } \\
\text { solution }\end{array}$ & $\begin{array}{l}\text { Percentage } \\
\text { inhibition } \\
\text { efficiency }(\eta \%)\end{array}$ \\
\hline 1. & 100 & 28.39 \\
\hline 2. & 300 & 46.18 \\
\hline 3. & 500 & 57.20 \\
\hline 4. & 700 & 61.22 \\
\hline 5. & 900 & 76.20 \\
\hline 6. & 1500 & 82.09 \\
\hline
\end{tabular}

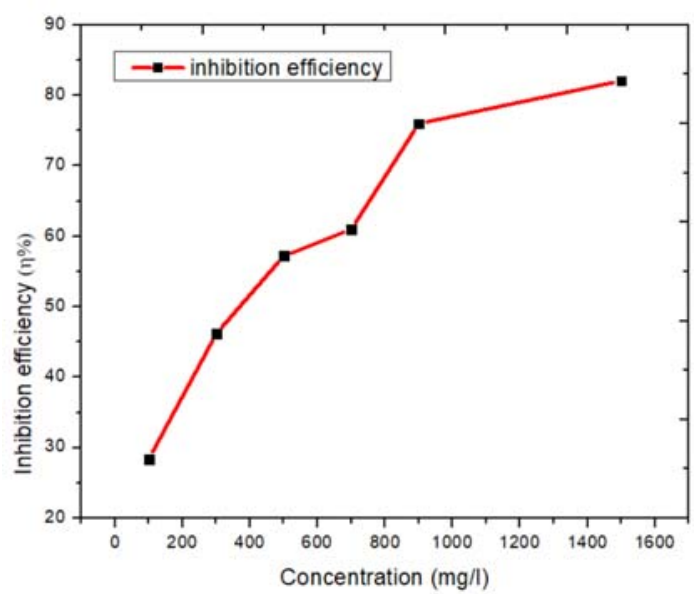

Fig. 1. Inhibition efficiency at various inhibitor concentrations. 


\section{UV-Visible spectroscopy}

The UV-Visible spectroscopic study demonstrates the shifts in the value of maximum absorbance and the position absorbance between the before and after immersion of MS specimens into the plant extract inhibitor in $1500 \mathrm{ppm}$ concentration submerged in $1 \mathrm{M} \mathrm{HCl}$ solution for 24 hours, indicating the development of a metal complex, as shown in Fig.2. This is observed at wavelength range of 200 to $800 \mathrm{~nm}$ by using UV-Vis spectrophotometer (UV-1900, Shimadzu)

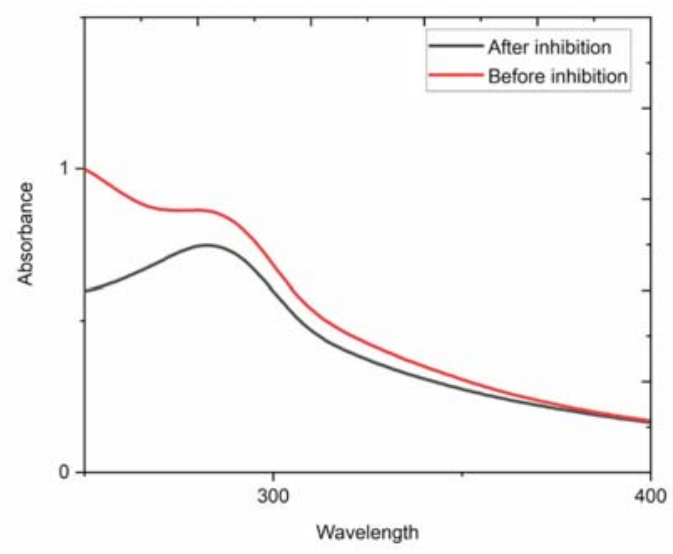

Fig. 2. UV spectra of the acidic solution of extract before and after corrosion tests.

\section{Adsorption isotherm-}

The surface coverage data is used to determine the adsorption process, which is crucial for predicting the isotherm. The adsorption isotherm can provide enough information about the inhibitor's interaction with the metal surface. The degree of surface covering for various concentrations of $\mathrm{A}$. sabulatum extract was calculated using the weight loss method. The corrosion inhibitor decreases metal corrosion by adsorption on the metal surface, after that, a protective layer is created. Various isotherms, including Langmuir, Frumkin, and El-awady, were used to match experimental data, in order to analyse the adsorption behaviour of Amomum sabulatum plant extract.

\section{Langmuir adsorption isotherm-}

The Langmuir isotherm is predicated on the presumption that the molecules that are adsorbed behaves exactly as they should, and create a monolayer. The adsorbate and adsorbent molecules have no lateral interactions. The Langmuir adsorption isotherm equation is

$$
\mathrm{C} / \theta=1 / \mathrm{K}+\mathrm{C}
$$

Where $\mathrm{K}$ is the inhibitor adsorption equilibrium constant, $\mathrm{C}$ is concentration, and $\theta$ is the proportion of the inhibitory coating on the metal surface as an adsorption value. Because the Langmuir plot is linear, it's possible that the experimental data for A. sabulatum plant extract follows the Langmuir adsorption isotherm. The Langmuir isotherm provided the best fit (strong correlation $\mathrm{R}_{2}=$ 1.29811). A straight line emerged from a plot of $\mathrm{C} / \theta$ against concentration, demonstrating the inhibitor adsorption on a monolayer over the mild steel surface, as shown in Fig. 3. This shows that in the 1 $\mathrm{M} \mathrm{HCl}$ media, the inhibitor (plant extract) follows the Langmuir adsorption isotherm. It means that the adsorbing A. sabulatum plant extract binds to the metal/solution contact in the normal adsorption sites.

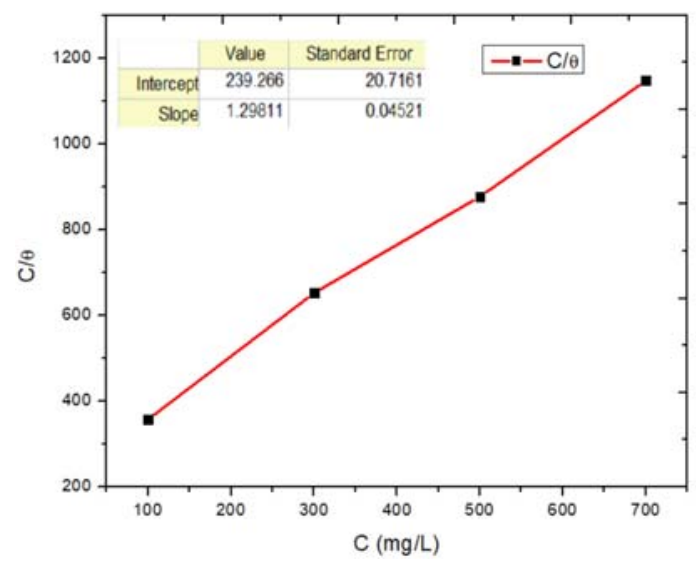

Fig. 3. Langmuir adsorption isotherm of the Amomum sabulatum extract.

El-awady adsorption isotherm- the equation for this isotherm is:

$\log \left[\frac{\theta}{1-\theta}\right]=\log \mathrm{K}+\mathrm{y} \log \mathrm{C}$

Plotting $\log \left(\frac{\theta}{1-\theta}\right)$ against $\log \mathrm{C}$ for the extract, where straight line relationships were obtained suggesting the validity of this model for the present case.

Where $\mathrm{C}$ is the extract concentration, $\theta$ is the degree of surface covering, $\mathrm{K}_{\mathrm{ad}}$ is the adsorption process equilibrium constant, and $\mathrm{K}_{\mathrm{ad}}=\mathrm{K}^{1 / \mathrm{y}}$. The number of active sites $\mathrm{y}$ is incorporated in this model. Multilayer adsorption is shown by $1 / \mathrm{y}$ values less than one, but if $1 / y$ is larger than one, the inhibitor molecule is occupying more than one active site. This plot produced straight lines, indicating that the data suited the isotherm nicely, as shown in Fig. 4. 


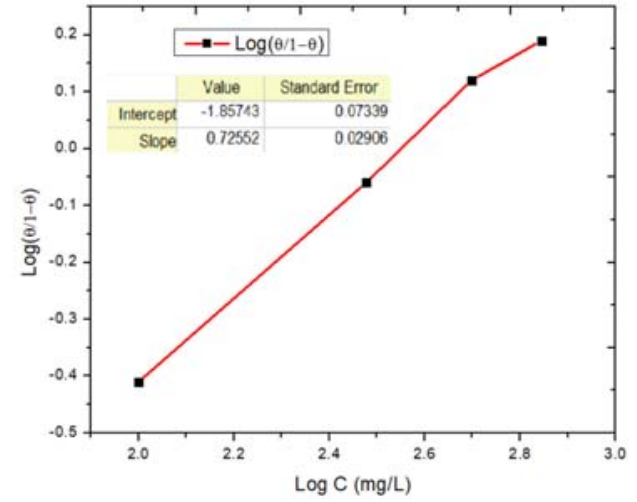

Fig. 4. El awadi adsorption isotherm of the Amomum sabulatum extract.

\section{SEM}

The surface morphological changes were monitored using a scanning electron microscope with a $20 \mathrm{keV}$ accelerating voltage. MS plates were polished with emery paper before being dipped in media of $1 \mathrm{M} \mathrm{HCl}$ for 24 hours in the presence and absence of $1500 \mathrm{ppm}$ inhibitors. SEM observations revealed the creation of a surface protective coating on the MS surface by the green inhibitors.

The surface of a clean mild steel specimen appears to be perfectly fine, yet the mild steel specimen without inhibitor appears to be seriously injured. The mild steel had been soaked in corrosive medium, which caused the surface to corrode, whereas the surface of the inhibited steel coupon is significantly enhanced due to the inhibitor's adsorption. The SEM images of cleaned steel surface, corroded and inhibited steel surfaces are shown in Fig. 5, Fig. 6 and Fig. 7 respectively.

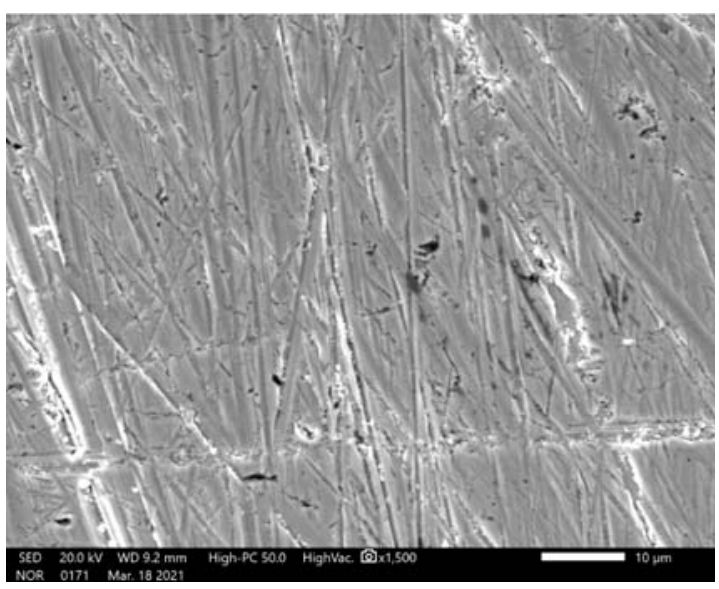

Fig. 5. SEM micrograph of cleaned steel surface.

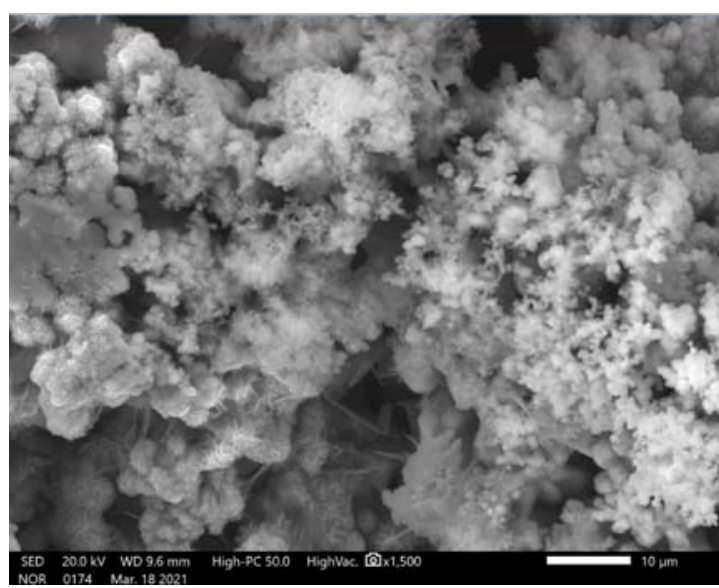

Fig. 6. SEM micrograph of corroded steel surface.

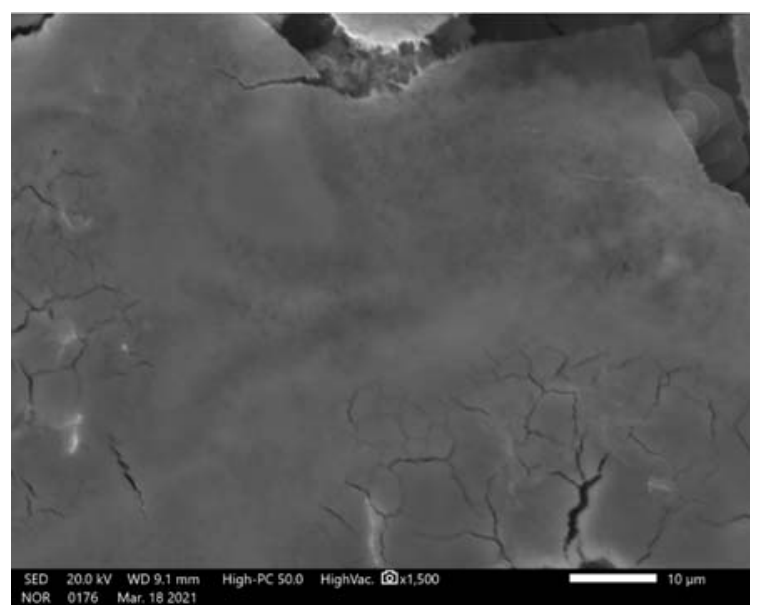

Fig. 7. SEM micrograph of inhibited steel surface.

\section{Conclusion}

The extract of Amomum sabulatum was tested for the anti-corrosive behavior and it is found to have $82.09 \%$ inhibition efficiency for steel in acidic medium. The results obtained from surface analysis are in favor of the formation of a protective layer on the steel surface which can resist corrosion.

\section{References:}

1. M. A. El-Hashemy, A. Sallam, "The inhibitive action of Calendula officinalis flower heads extract for mild steel corrosion in $1 \mathrm{M} \mathrm{HCl}$ solution," J. Mater. Res. Technol., Vol 9, issue 6, Page 13509-13523, 2020.

2. A. Sedik, D. Lerari, A. Salci, S. Athman, K. Bachari, 'I.H. Gecibesler, R. Solmaz, "Dardagan Fruit extract as eco-friendly corrosion inhibitor for mild steel in $1 \mathrm{M} \mathrm{HCl}$ : Electrochemical and 
surface morphological studies," J Taiwan Inst. Chem. Eng., Vol. 107, Page 189-200, 2020.

3. A. Dehghani, G. Bahlakeh, B. Ramezanzadeh, M. Ramezanzadeh, "Integrated modeling and electrochemical study of Myrobalan extract for mild steel corrosion retardation in acidizing media," J. Mol. Liq., Vol. 298, 2020.

4. A. Saxenaa, K. K. Thakura, N. Bhardwaj, "Electrochemilogycal studies and surface examination of low carbon steel by applying the extract of Musa acuminata," Surf. Interfaces, Vol. 18, 2020.

5. Ahanotu, I. B. Onyeachu, M. M. Solomon, I. S. Chikwe, O. B. Chikwe, C. A. Eziukwu, “ Pterocarpus santalinoides leaves extract as a sustainable and potent inhibitor for low carbon steel in a simulated pickling medium," Sust. Chem. Pharm., Vol. 15, 2020.

6. I. Chung, R. Malathy, R. Priyadharshini, V. Hemapriya, S. Kim, M. Prabakaran, “ Inhibition of mild steel corrosion using Magnolia kobus extract in sulphuric acid medium," Mater. Today Commun, Vol. 25, 2020.

7. S. Umoren, U.M. Eduok, M.M. Solomon, A.P. Udoh, "Corrosion inhibition by leaves and stem extract of Sida acuta for mild steel in $1 \mathrm{M} \mathrm{H} 2 \mathrm{SO} 4$ solutions investigated by chemical and spectroscopic techniques," Arabian J. Chem., Vol.9, page 209-224, 2011.

8. Xianghong Li, S. Deng, Hui Fu, "Inhibition of the corrosion of steel in $\mathrm{HCl}, \mathrm{H}_{2} \mathrm{SO}_{4}$ solutions by bamboo leaf extract," Corros. Sci., vol. 62, page 163-175, 2012.

9. Lingjie Li, X. Zhang, J. Lei, J. He, S. Zhang, F. Pan, "Adsorption and corrosion inhibition of Osmanthus fragran leaves extract on carbon steel," Corros. Sci., Vol. 63, page 82-90, 2012.

10. S. Garai, S. Garai, P. Jaisankar, J. Singh, A. Elango, "A comprehensive study on crude methanolic extract of Artemisia pallens (Asteraceae) and its active component as effective corrosion inhibitors of mild steel in acid solution," Corros. Sci., Vol. 60, page 193-204, 2012.

11. N. Soltani, N. Tavakkoli, M. Khayatkashani, M. Jalali, A. Mosavizade, "Green approach to corrosion inhibition of 304 stainless steel in hydrochloric acid solution by the extract of Salvia officinalis leaves," Corros Sci, Vol. 62, page 122$135,2012$.

12. M. Otaibi, A. Mayouf, M. Khan, A. Mousa, S. Mazroa , H. Alkhathlan, "Corrosion inhibitory action of some plant extracts on the corrosion of mild steel in acidic media," Arabian J. Chem., Vol. 7, Issue 3, page 340-346, 2012.
13. Xianghong Li, S. Deng, "Inhibition effect of Dendrocalamus brandisii leaves extract on aluminum in $\mathrm{HCl}, \mathrm{H}_{3} \mathrm{PO}_{4}$ solutions," Corros. Sci., Vol. 65, page 299-308, 2012.

14. X.Zhang, X. Yang, T. Gu, Y. Cao, C. Lu, "Antimicrobial polycyclic polyprenylated acylphoroglucinols from Mesua ferrea flower," Phytochem. Lett., Vol. 40,Page 84-88, 2020.

15. A. Dehghani, G. Bahlakeha, B. Ramezanzadehb, M. Ramezanzadeh, "Potential of Borage flower aqueous extract as an environmentally sustainable corrosion inhibitor for acid corrosion of mild steel: Electrochemical and theoretical studies," $J$. Mol. Liq., Vol. 277, page 895-911, 2019.

16. A. Dehghani, G. Bahlakeha, B. Ramezanzadeh, “ A detailed electrochemical/theoretical exploration of the aqueous Chinese gooseberry fruit shell extract as a green and cheap corrosion inhibitor for mild steel in acidic solution," J. Mol. Liq., Vol. 282, page 366-384, 2019.

17. A. Pandey, S. Tripathi "Concept of standardization, extraction and pre phytochemicals screening strategies for herbal drug," J. Pharmacogn. Phytochem., 2014.

18. A. Ismail, E. Mohamed, M. Marghany, F. AbdelMotaal, I. Abdel-Farid, M. El-Sayed, "Preliminary phytochemical screening, plant growth inhibition and antimicrobial activity studies of Faidherbia albida legume extracts," J. Saudi Soc. Agric. Sci., Pages 112-117, 2016.

19. A. Alqethami, A. Aldhebiani, "Medicinal plants used in Jeddah, Saudi Arabia: Phytochemical screening," Saudi J. Biol. Sci., Pages 805-812, 2021.

20. M. Boudalia, R. Fernández-Domene, M. Tabyaoui, A. Bellaouchou, A. Guenbour,J. García-Antón, "Green approach to corrosion inhibition of stainlesssteel in phosphoric acid of Artemesia herbaalbamedium using plant extract," J. Mater. Res. Technol, Pages 5763-5773, 2019.

21. H. Bourazmi, M. Tabyaoui , L. EL Hattabi, Y. El Aoufir, E. Ebenso, A. Ansari, "Camphor as an effective corrosion inhibitor for carbon steel in $1 \mathrm{M} \mathrm{HCl}$ solution: electrochemical and quantum chemical investigation," J. Mater. Environ. Sci., Page 1058-1074, 2018.

22. M. T. Saeed, M. Saleem, S. Usmani, I. A. Malik, F. A. Al-Shammari , K. M. Deen, "Corrosion inhibition of mild steel in $1 \mathrm{M} \mathrm{HCl}$ by sweet melon peel extract," J. King Saud Univ. Sci., Page 1344-1351, 2019.

23. A. Bribri, M. Tabyaoui, B. Tabyaoui, H. Attari, F. Bentiss, "The use of Euphorbia falcata extract as eco-friendly corrosion inhibitor of carbon steel in hydrochloric acid solution," Mater. Chem. Phys., vol. 141, Issue 1, page 240-247, 2013. 
24. P. Raja, A. Qureshi, A. Rahim, H. Osman, K. Awang "Neolamarckia cadamba alkaloids as ecofriendly corrosion inhibitors for mild steel in $1 \mathrm{M}$ HCl media," Corros. Sci., Volume 69, page 292301, 2013.

25. E. Alibakhshi, M. Ramezanzadeh, G. Bahlakeh, B. Ramezanzadeh, M. Mahdavian, M Motamedi, "Glycyrrhiza glabra leaves extract as a green corrosion inhibitor for mild steel in $1 \mathrm{M}$ hydrochloric acid solution: Experimental, molecular dynamics, Monte Carlo and quantum mechanics study," J. Mol. Liq., Vol. 255, page 185-198, 2018.

26. A. Dehghani, G. Bahlakeha, B. Ramezanzadeh, "Green Eucalyptus leaf extract: A potent source of bio-active corrosion inhibitors for mild steel," Bioelectrochem" Vol. 130, 2019.

27. P. Muthukrishnan, B. Jeyaprabha, P. Prakash, "Adsorption and corrosion inhibiting behavior of Lannea coromandelica leaf extract on mild steel corrosion," Arabian J. Chem., 2013.

28. H. Hassannejad, A. Nouri, "Sunflower seed hull extract as a novel green corrosion inhibitor for mild steel in $\mathrm{HCl}$ solution," $J$. Mol. Liq., Vol. 254, page 377-382, 2018.

29. A. Jmiai, B. Ibrahimi, A. Tara, M. Chadili, S. E. Issami, O. Jbara, A. Khallaayoun, L. Bazzi, "Application of Zizyphus Lotuse - pulp of Jujube extract as green and promising corrosion inhibitor for copper in acidic medium," J. Mol. Liq., Vol. 268, Page 102-113, 2018.

30. S.A. Umoren, Z.M. Gasem, I.B. Obot, Date palm (Phoenix dactylifera) leaf extract as an ecofriendly corrosion inhibitor for carbon steel in $1 \mathrm{M}$ hydrochloric acid solution, Anti-

31. A Gupta, D Kundalkar, KK Saxena, Investigation on deformation of Inconel alloy 751, Materials Today Proceedings, 45, 5377-5380.

32. Y Gajalappa, A Krishnaiah, KB Kumar, KK Saxena, P Goyal, Flow behaviour kinetics of Inconel 600 superalloy under hot deformation using gleeble 3800, Materials Today: Proceedings $45,5320-5322$

33. P Yadav, G Beniwal, KK Saxena, A review on pore and porosity in tissue engineering, Materials Today Proceedings 